\title{
Evidence on the Temporal Stability of the Demand for Money Relationship in the United States
}

\author{
R. W. HAFER AND SCOTT E. HEIN
}

\section{inter}

CONOMISTS and policymakers are extremely interested in the temporal stability of the money demand relationship. Most economists use macroeconomic models which assume that money demand is consistently related to a number of predetermined variables. As such, evidence of instability in the rem lationship casts doubt on the validity of such models.

Evidence of temporal instability is likewise disconcerting to monetary policymakers. When the relationship between money demand and the variables that determine it breaks down, policymakers by definition are unsure of future money demand. Thus, projecting the linkage between the money stock and economic variables such as output, prices, and interest rates becomes even more diffoult and tenuous than before.

With regard to narrowly defined money (M1), the evidence on the stability of the demand relationship has recently taken a drastic turn. Prior to the mid1970s, the evidence supporting a stable money demand relationship in the United States was "overwhelming," to borrow Laidler's description. ${ }^{I}$ Along the same line, Laumas and Mehra provided statistical evidence that the relationship was stable under a broad range of alternative specifications. ${ }^{2}$

\footnotetext{
1David E. W. Laidler, "The Influence of Money on Economic Activity: A Survey of Some Current Problems," in G. Clayton. J. C. Gilbert, and R. Sedgwick, eds., Monetary Theory and Policy in the 1970's, (London: Oxford University Press, 1971).

${ }^{2}$ G. S, Laumas and Y. P. Mehra, "The Stability of the Demand for Money Function: The Evidence from Quarterly Data," The Review of Economics and Statistics (November 1976), pp. 463-68.
}

In 1976, however, two separate studies found evidence which suggests that the money demand relationship had broken down around 1973. Both Enzler, Johnson, and Paulus (EJP), and Goldfeld found that the traditional transaction money demand relationship significantly overpredicted post-1972 real money balances. ${ }^{3}$ Being unsuccessful in attempting to explain the decline statistically, both studies concluded that there had indeed been a downward shift in the relationship over this period.

This conclusion recently has come under attack in a number of studies which resurrect concern about the appropriate money demand specification. These studies argue that other specifications of the money demand relationship do not indicate any recent breakdown. This article provides a critical review of the existing evidence on the issue of the temporal stability of the money demand relationship. Various money demand specifications are examined in terms of their dynamic out-of-sample predictive ability over the post1972 period and more formally through the use of the Brown-Durbin-Evans (BDE) cusum-squares tests. ${ }^{4}$ The forecasting ability of these alternatives is compared using a common sample period, data base, and means of generating post-sample predictions.

\footnotetext{
3 Jared Enzler, Lewis Johnson, and John Paulus, "Some Prob" lems of Money Demand" Brookings Papers on Economic Activity (1: 1976) pp. 261-79; Stephen M. Goldfeld, "The Case of the Missing Money," Brookings Papers on Economic Activity (3: 1976$)$, pp. 683-730.

4R. L. Brown, I. Durbin, and I. M. Evans, "Techniques for Testing the Constancy of Regression Relationships Over Time," Journal of the Royal Statistical Society, Ser. B, Vol. 37, (No. 2, 1975), pp. 149-92.
} 


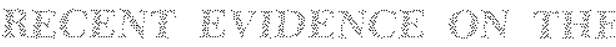

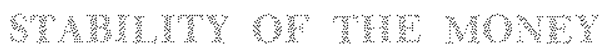

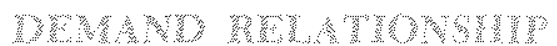

The basic Goldfeld equation, which posits a real adjustment lag, provides the standard of comparison for alternative money demand specifications. ${ }^{5}$ The real adjustment version of the Goldfeld specification is

$$
\begin{gathered}
\ln \left(\frac{M_{t}}{P_{t}}\right)=\alpha_{4}+\alpha_{1} \ln y_{t}+\alpha_{2} \ln \text { CPR }_{t}+ \\
\alpha_{3} \ln \text { RTD }_{\mathrm{t}}+\alpha_{4} \ln \left(\frac{M_{t-1}}{P_{t-1}}\right)+v_{t},
\end{gathered}
$$

where $\mathbf{M}=$ nominal $\mathrm{M} 1$ balances,

$\mathbf{P}=$ the general price level (the implicit GNP deflator),

$y=$ real income (real GNP),

$\mathrm{CPR}=$ the commercial paper rate,

RTD = the rate on time deposits,

$v=$ an error term. ${ }^{8}$

The first row of table 1 reports the coefficient estimates and summary statistics for this money demand specification. All estimates shown are for the sample period II/1955-IV/1972 and are based on the Cochrane-Orcutt (CORC) estimation technique. In addition, table 1 reports the root-mean-squared error (RMSE) of the dynamic post-sample simulations (I/1973-I/1977). ${ }^{7}$

5The equation hypothesizes that the real money stock only partially adjusts to the desired level in the current quarter (the desired level being determined by real income and the two contemporaneous interest rates). Another popular version of the partial adjustment process hypothesizes that the nominal money stock partially adjusts to the desired level within one quarter. This version is similar to equation 1 in all respects except that the lagged money stock variable is divided by the contemporaneous price level. It should be noted that Goldfeld foutd the nominal adjustment mechanism slightly preferable in terms of out-of-sample forecasting ability. We use his real version, however, since it has become the standard reference equation in most studies considered here.

"Since Goldfeld estimates equation 1 by the Cochrane-Orcutt (CORC) estimation procedure, he implicitly assumes $v_{t}=$ $\rho v_{t-t}+\varepsilon_{t}$, where $\rho$ is a constant and $\varepsilon$ is an error term with classical properties. In theory, the coexistence of a lagged dependent variable and serially correlated error terms casts doubt about the consistency and efficiency of CORC estimates. However, the work of Laumas-Spencer suggests that the gains from more elaborate estimation procedures are small See G. S. Laumas and David E. Spencer, "The Stability of the Demand for Money: Evidence from the Post-1973 Period," unpublished manuscript, 1979.

7Two important points about the post-sample simulations need to be noted. In the first place, the simulations are based on the transformed equation, in which the autocorrelation in the error terms is explicitly recognized. $I_{n}$ other words, the forecasts are based on the equation

$$
\ln \left(\frac{M_{t}}{P_{t}}\right)=\hat{\alpha}_{\rho}(1-\hat{\rho})+\hat{\alpha}_{t}\left(\ln _{\mathrm{t}} \mathrm{y}_{\mathrm{t}}-\hat{\rho} \ln \mathrm{y}_{\mathrm{t}-1}\right)+
$$

$\hat{\alpha}_{z}\left(\ln \mathrm{CPR}_{\mathrm{t}}-\hat{\rho} \ln \mathrm{CPR}_{\mathrm{t}-\mathrm{s}}\right)+\hat{\alpha}_{\mathfrak{3}}\left(\ln \mathrm{RTD}_{\mathrm{t}}-\hat{\rho} \ln \mathrm{RTD}_{t-1}\right)+$

$$
\hat{\alpha}_{4}\left[\ln \left(\frac{M_{t-1}}{P_{t-1}}\right)-\hat{\rho} \ln \left(\frac{M_{t-2}}{P_{t-2}}\right)\right]+\hat{\rho} \ln \left(\frac{M_{t-1}}{P_{t-1}}\right)
$$

where $\hat{\rho}$ is the estimated serial correlation coefficient and $\hat{\alpha}_{1}$
Although the sample period is slightly different, the results for this equation are similar to Goldfeld's. The estimated coefficients all have the anticipated sign and are significantly different from zero. These estimates reveal that more than one third of the desired change in the money stock is completed within one quarter and that the long-run income elasticity is 0.54 . The resulting large RMSE for the dynamic simulation demonstrates a marked deterioration in the relationship after 1972. A comparable simulation over the period IV/1968-IV/1972 yielded an RMSE of only 2.33 - merely one-tenth of that found for the post1972 period.

One of the earliest rebuttals to the instability claim came from Hamburger, who contended that EJP and Goldfeld were too restrictive in their choice of asset yields hypothesized to affect money demand. ${ }^{8} \mathrm{He}$ argued that the exclusion of long-term asset yields from the specification was both theoretically and empirically unjustified.

To support his argument, Hamburger incorporated long-term govemment bond yields and the common stock dividend-price ratio in estimating an altered version of the MPS (MIT-Pennsylvania-Social Science Research Council) money demand equation. The adapted specification used by Hamburger was

$$
\begin{gathered}
\ln \left(\frac{M_{t}}{P_{t} y_{t}}\right)=\beta_{0}+\beta_{1} \ln \mathrm{RTD}_{t}+\beta_{2} \ln \mathrm{DPR}_{t}+ \\
\beta_{3} \ln \mathrm{RGL}_{\mathrm{t}}+\beta_{4} \ln \left(\frac{M_{t-1}}{\mathbf{P}_{\mathrm{t}} \mathrm{y}_{\mathrm{t}}}\right)+\mathrm{e}_{\mathrm{t}}
\end{gathered}
$$

where DPR is the dividend-price ratio on common stock, RGL is the yield on long-term government bonds, $e$ is an error term, and other variables are as previously defined.

Estimation results for this equation are reported in the second row of table $1 .^{9}$ These results, similar to

$(i=0, \ldots, 4)$ is the estimated regression coefficient. It is unclear from the cited studies whether such a procedure is commonly followed. Second, the RMSE for each equation is determined by comparing the actual money stock with the nominal level simalated by each equation. Many previous studies use the real money stock and projected real balances as the source of comparison.

The endpoint of our sample period (1/1977) was chosen to enhance the comparability between our findings and others considered here. Also, the series for net wealth used in this study was available only through $1 / 1977$.

MMichael I. Hamberger, "Behavior of the Money Stock: Is There a Puzzle?" Joumal of Monetary Economics, (No. $3_{x}$ 1977), pp. $265-288$.

${ }^{9}$ This equation is based on the nominal adjustment mechanism discussed in footnote 5 . We also estimated the equation assuming a real adjustment mecharism in which the lagged money stock is deflated by the term $\left(P_{\mathrm{r}+1} y_{\mathrm{t}}\right)$. Except for the coeficient on the commercial bank passbook rate, which was insigIiffcantly different from zero, the coefficient estimates were similar to those reported in table 1 . However, the RMSE increased dramatically to 14.59 when the real adjustment version was employed. 


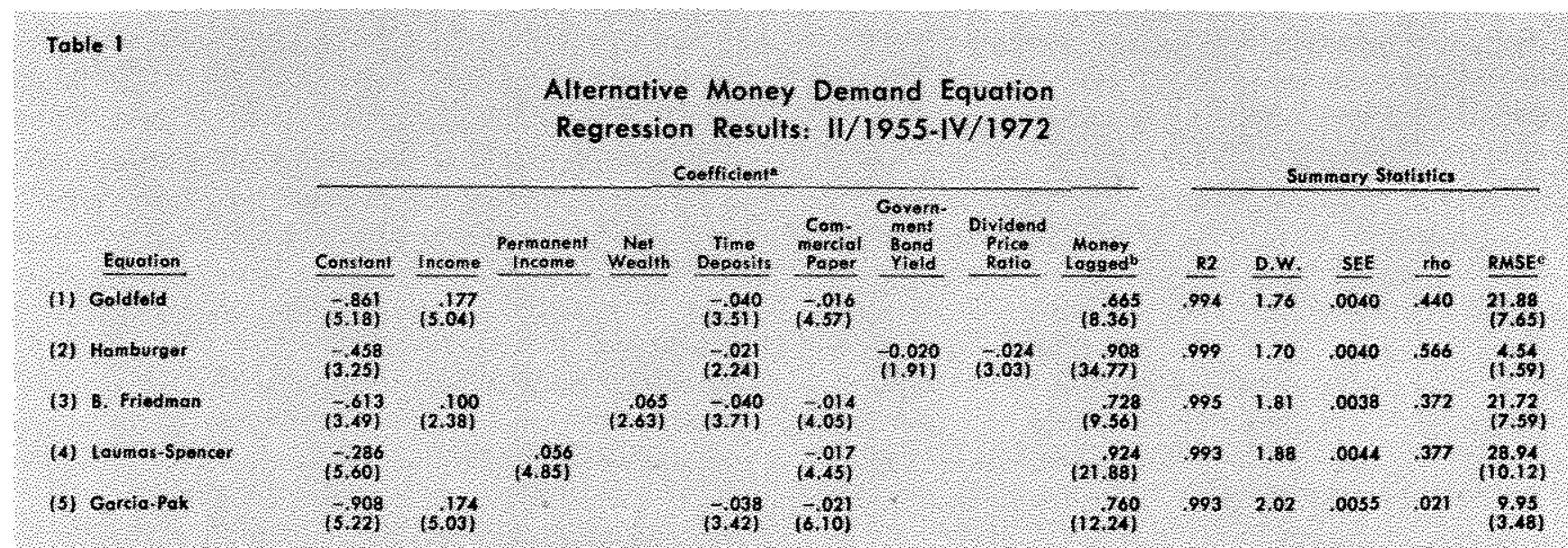

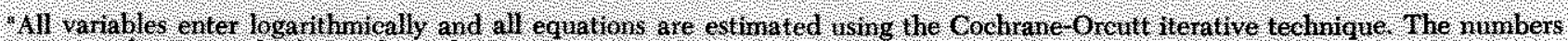
in paretilieses are absolute valites of $t$ ratlos.

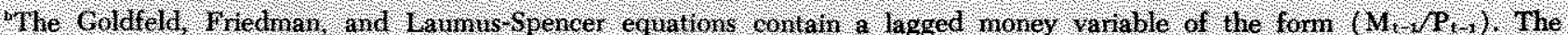

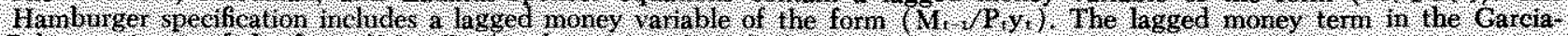

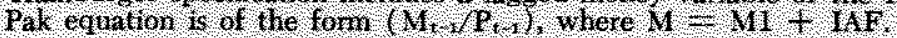

The MVSE is lhe root-nean-squared error for dyramic extrapolation over the $1 / 1973 / 1 / 977$ period, The error is in billons of cument dollars, apd the pereentage error - he hMSE relative to the nean level of MI balances over the post-sarnple period - is listed in parentheses.

Hamburger's, indicate that "long-term" yields have a significant effect on money demand. Furthermore, the equation performs quite well relative to Goldfeld's equation in post-sample simulations.

Important differences between the Goldfeld and Hamburger estimation results should be noted, however. First, Hamburger's specification implies that less than 10 percent of the change in the desired money stock occurs within one quarter, much slower than the 34 percent adjustment suggested by Goldfeld. ${ }^{10}$ In addition, Hamburger's specification, by excluding real income as a separate independent variable, has constrained the long-run income elasticity to be unity. ${ }^{11}$ This, again, is quite different from the 0.54

${ }^{10}$ It is interesting to note that the relatively slow speed of adjustment found for this specification is not wholly attributable to the use of a nominal adjustment specification as has been found in other cases. When Hamburger's equation is reestimated using a real adjustment mechanism, the estimated speed of adjustment declines to 7 percent per quarter.

${ }^{11}$ This may be shown formally by considering the nominal adjustment mechanisn used by Hamburger:

$$
\begin{aligned}
& \frac{\mathrm{M}_{\mathrm{t}}}{\mathrm{M}_{\mathrm{t}-\mathrm{s}}}=\left[\frac{\mathrm{M}_{\mathrm{t}}^{*}}{\mathrm{M}_{\mathrm{t}-\mathrm{I}}}\right]^{\lambda} \\
& \left.\frac{\mathrm{M}_{\mathrm{t}}}{\mathrm{P}_{\mathrm{t} \mathrm{t}_{\mathrm{t}}}}=\frac{\frac{\mathrm{M}_{\mathrm{t}}}{\mathrm{M}_{\mathrm{t}-1}}}{\mathrm{P}_{\mathrm{t}} \mathrm{y}_{\mathrm{t}}}\right]^{\lambda}
\end{aligned}
$$

which, after aking the logarithm and rearanging, yelds

$$
\ln \left(\frac{M_{t}}{P_{t} y_{t}}\right)=\lambda \ln \left(\frac{M_{t}^{*}}{P_{t} y_{t}}\right)+(1-\lambda) \ln \left(\frac{M_{t-1}}{P_{t} y_{t}}\right) .
$$

Retuming to equation 2 in the text, we see that Hamburger's specification implies, estimate yielded by Goldfeld's equation. Finally, while Goldfeld was criticized for excluding long-term yields from the relationship, Hamburger equally can be criticized for excluding short-term rates other than the passbook rate. This exclusion creates problems when Regulation $Q$ prevents the commercial passbook rate from moving in step with other short-term yields. Thus, Hamburger has no good proxy in the equation to pick up movements in freely fluctuating short-term yields.

Friedman has criticized Hamburger's conclusion that long-term asset yields provide the key to understanding the recent money demand problem. ${ }^{12}$ Friedman's analysis considered aggregate wealth as a separate determinant of money demand. Arguing that Hamburger's dividend-price ratio variable is simply a proxy for aggregate wealth, Friedman replaced the equity yield in Hamburger's specification with aggregate household financial asset holdings and obtained a net improvement in post-sample predictive ability. Based

$\lambda \ln \frac{M_{i}^{*}}{P_{\mathrm{t}} y_{\mathrm{t}}}=\beta_{\mathrm{t}}+\beta_{\mathrm{i}} \ln \mathrm{RTD}_{\mathrm{t}}+\beta_{\mathrm{z}} \ln \mathrm{DPR}+\beta_{\mathrm{t}} \ln \mathrm{RGL}_{\mathrm{t}}+\mathrm{et}_{\mathrm{t}}$ and $\beta_{s}=1-\lambda$. From this it is clear that $\frac{\partial \ln \mathrm{M}_{\mathrm{t}}^{o}}{\partial \ln \mathrm{y}_{\mathrm{s}}}=1$, so that Hamburger's equation constrains the long-run income elasticity to be unity. Hamburger"s specification can be criticized further on the gromds that he includes a real rate of return when a nominal rate is appropriate.

12Benjamin Friedman, "Crowding Out or Crowding ra: Ecotomic Consequences of Financing Goverment Deficits." Brookings Papers on Economic Activity (3: 1978), pp. 593641. 
on this finding, he conjectured that ". . . Hamburger's proposed solution for the mystery of the missing money is simply a disguised story about the role of wealth in the money-demand function, and that the solution works better without the disguise."1s

Were this true, however, one would also expect the inclusion of a wealth measure in a conventional equation (such as Goldfeld's) to yield more reliable postsample forecasts. The estimated results for such a specification are reported in the third row of table 1 . Although the wealth variable (measured here by household net worth) does have a significant effect on money demand, it does little to improve postsample predictions.

These results do not support Friedman's interpretation of Hamburger's finding. ${ }^{14}$ According to this interpretation, the inclusion of a wealth variable in any specification should improve the equation's predictive ability. When incorporated in Goldfeld's equation, it did not. This suggests that the inclusion of a proxy for real wealth is not the crucial feature of Hamburger's specification.

Laumas and Spencer examined the applicability of permanent income-measured as an exponentially weighted average of past values of real GNP - as the scale variable in the money demand relationship. ${ }^{15}$ The relevance of such a variable is explored in the fourth row of table $1 .^{10}$ The estimation results of this equation are similar to Laumas and Spencer's. They imply a slow speed of adjustment ( 8 percent per quarter), similar to that of Hamburger's specification. On the other hand, the coefficient estimates yield a long-run permanent income elasticity that is less than unity (0.74). This specification, however, performs worse than the original Goldfeld equation over the post-sample period which suggests that permanent income, at least measured adaptively, is not a soltttion to the puzzle. Our findings (not detailed here) further indicate that this conclusion is insensitive to the measurement of interest rates.

Finally, Garcia and Pak have suggested that the recent problem stems from the use of an improperly

\footnotetext{
18Ibid, p. 629 .

14 Interestingly enough, Friedman also finds that the inclusion of a wealth variable in Goldfeld's specification yields an unstable relationship, at least based on a "Chow test." This finding should have cautioned him against viewing Hamburger's solution as based on finding a proxy for wealth, since wealth itself does not appear to make the relationship stable.

15Laumas-Spencer, "The Stability of the Demand for Money."

16 We used the same real permanent income series as Laumas and Spencer. It was kindly provided to us by David Spencer.
}

measured money stock. ${ }^{17}$ They argue that the recent widespread use of repurchase agreements has led to an important underestimation of "true" M1 balances.

The final equation of table 1 investigates this argument by including immediately available funds (IAF) data in the measurement of the money stock. ${ }^{18}$ In all other respects, this equation is analogous to Goldfeld's. The coefficient estimates are similar to the estimates obtained for Goldfeld's specification. The standard error of the equation, however, is larger, which suggests a poorer sample period fit. While this equation predicts post-1972 M1 balances better than the Goldfeld equation, it is unclear whether this alone justifies the conclusion that the relationship is stable.

An examination of the forecasting ability of these alternative money demand equations indicates that the inclusion of neither permanent income nor wealth in the conventional equation significantly improves post-sample forecasts. Also, while the addition of repurchase agreements to $\mathrm{Ml}$ improves the post-sample predictions, the significance of the improvement remains unclear. Although Hamburger's specification does a superior job in forecasting money balances, the source of the improvement is puzzling.

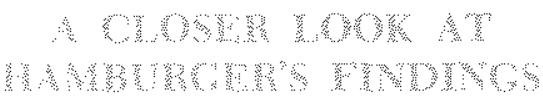

As noted in the previous section, Hamburger's specification performs quite well in predicting post-1972 money balances. His specification, however, differs from the conventional equation not only in its incorporation of long-term asset yields, but also in its treatment of the long-run income elasticity and its exclusion of short-term interest rates.

Consider, first, the issue of the long-run income elasticity. Hamburger's specification constrains the long-run income elasticity to be unity while the others suggest that the long-run income elasticity is signif-

17Gillian Garcia and Simon Pak, "Some Clues in the Case of the Missing Money," American Economic Review, Papers and Proceedings (May 1979), pp. 330-34.

18The IAF data used in the present study is taken from Gillian Garcia and Simon Pak "The Ratio of Currency to Demand Deposits in the United States," The Journal of Finance (Jume 1979), pp. 703-15. It has been argued that the Garcia-Pak equation is misspecified because of the exclusion of the appropriate own interest rate on the repurchase agreements. Using federal funds rate as a proxy for such a rate, Porter, Simpson, and Mauskopf report that out-of-sample forecast errors (III/1974-1/1979) are higher than those based on the equation examined in the text. See Bichard D. Porter, Thomas D. Simpson, and Eileen Mauskopf, "Financial Innovation and the Monetary Aggregates,"Brookings Papers on Economic Activity (1: 1979), pp. 213-29. 


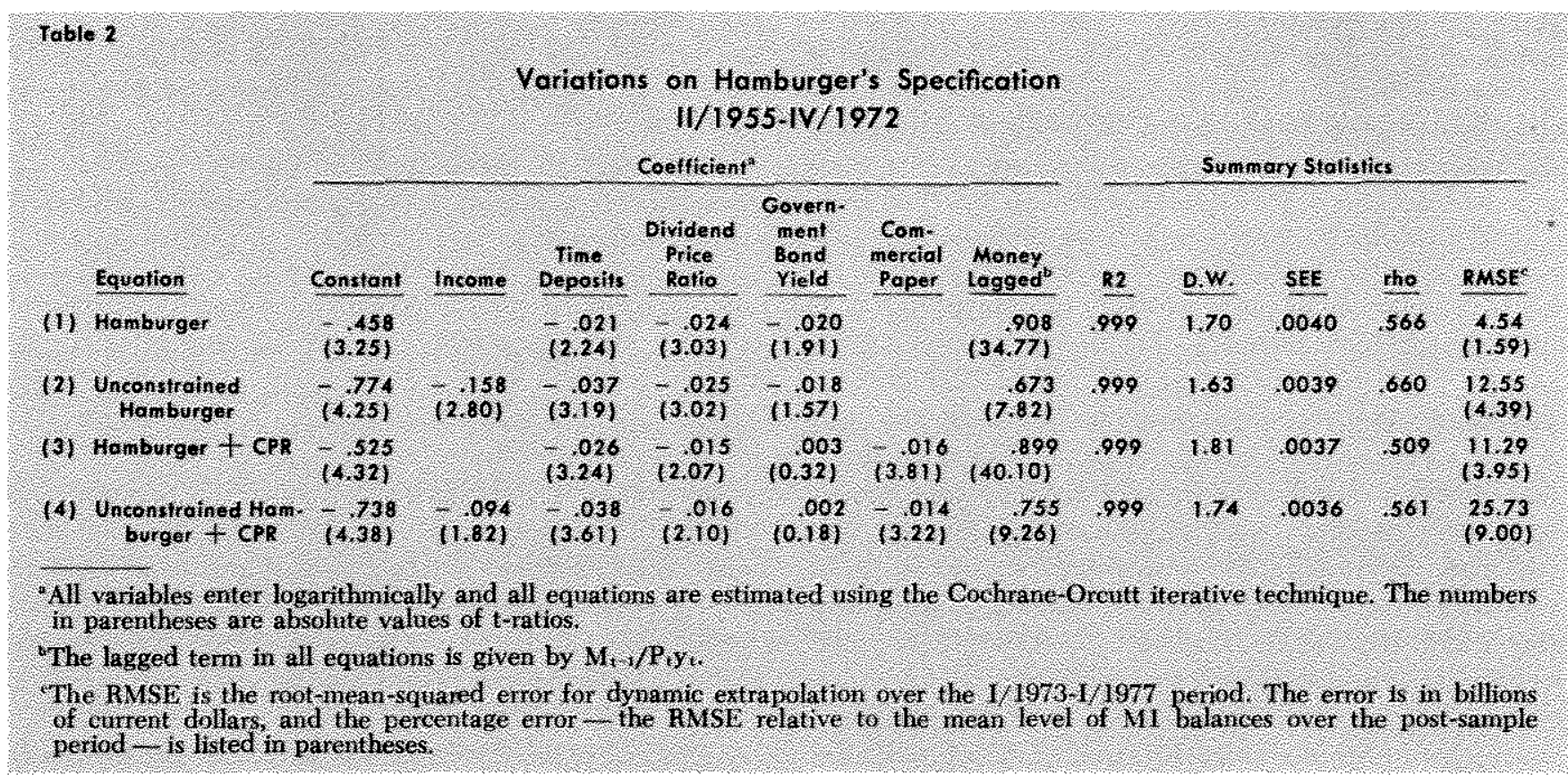

cantly less than one. Hamburger's constraint can be tested easily by adding the natural log of real income as a separate independent variable to his original specification. This allows the long-run income elasticity to be freely estimated. ${ }^{19}$

These estimation results are reported in the second row of table 2. The estimated coefficient on real income is negative and significantly different from zero, which suggests that the long-run income elasticity is less than unity. In fact, the estimation results indicate that this parameter is 0.52 - not much different from Goldfeld's equation. Incorporation of real income into the specification yields a larger estimate of both the speed of adjustment and the short-run interest elasticity on the time deposit variable. Also, the standard error of the equation is reduced slightly upon the relaxation of the income elasticity constraint. Thus, on empirical grounds, there is no apparent justifica-

19If real income is included in the specification as a separate variable, we have, following footnote 11 ,

$$
\begin{gathered}
\lambda \ln \left(\frac{\mathrm{M}_{t}^{*}}{\mathbf{P}_{\mathrm{t}} \mathrm{y}_{\mathrm{t}}}\right)=\beta_{0}+\beta_{1} \ln \mathrm{RTD}_{\mathrm{t}}+\beta_{\mathrm{z}} \ln \mathrm{DPR}_{\mathrm{t}}+ \\
\beta_{3} \ln \mathrm{RGL}_{\mathrm{t}}+\beta_{\mathrm{s}} \ln \mathrm{y}_{\mathrm{t}},
\end{gathered}
$$

(where $\beta_{4}(=1-\lambda)$ is the coefficient on the lagged variable) or,

$$
\begin{aligned}
\ln \left(\frac{\mathrm{M}_{\mathrm{t}}^{*}}{\mathrm{P}_{\mathrm{t}}}\right)= & \left(\beta_{\mathrm{q}} / \lambda\right)+\left(\beta_{1} / \lambda\right) \ln \mathrm{RTD}_{\mathrm{t}}+\left(\beta_{2} / \lambda\right) \ln \mathrm{DPR}_{\mathrm{t}}+ \\
& \left(\beta_{3} / \lambda\right) \ln \mathrm{RGL}_{\mathrm{t}}+\left(\beta_{\mathrm{t}} / \lambda+1\right) \ln \mathrm{y}_{\mathrm{t}} .
\end{aligned}
$$

This implies that the long-run income elasticity,

$$
\left(\frac{\partial \ln \left(\mathbf{M}_{\mathrm{t}}^{*} / \mathbf{P}_{\mathrm{t}}\right)}{\partial \ln \mathrm{y}_{\mathrm{t}}}\right) \text {, is }\left(\beta_{\mathrm{v}} / \lambda\right)+1 \text {, where }
$$

$\beta_{5}$ is the coefficient on the real income variable and $\lambda$ is the speed of adjustment. (Note again that Hamburger's specifica- tion for Hamburger's restriction that the income elasticity be unity.

Finally, note that the forecasting accuracy of this general specification (in terms of the RMSE) declines markedly relative to Hamburger's original specification. This suggests that an important characteristic of Hamburger's specification - as far as predictive ability is concerned - is the imposed income elasticity constraint. $^{20}$

Unlike most other specifications, which ignore longterm asset yields, Hamburger's equation excludes both short-term interest rates and (since nominal rates should incorporate expected inflation) short-term inflationary expectations as well. Row three of table 2 enumerates the results of adding the commercial paper rate to Hamburger's specification. As far as sample period estimation is concerned, this short-term rate has a significant negative impact on money demand. However, the estimated coefficient on the long-term government bond yield now becomes insignificantly different from zero.

As observed when the real income variable was added, the inclusion of the commercial paper rate

tion constrains $B_{s}$ to be zero, implying a long-run income elasticity of unity).

-20 As far as static predictive ability is concerned, Hamburger's specification can be further improved by constraining the income elasticity to values in excess of unity. See Scott $E$. Hein, "Empirical Evidence on the Macroeconomic Demand for Money Relationship in the United States," (Ph.D. dissertation, Purdue University, 1979). Hein argues that these forecasts are accurate because the specification is essentially an autoregressive process. 
improves the sample period fit, but only at the expense of post-sample predictive ability. Exclusion of short-term interest rates from the specification, although empirically unjustified, is partially responsible for Hamburger's superior forecasting results.

The addition of both real income and the commercial paper rate to the basic Hamburger specification has a significant impact on both sample period and post-sample period findings, as shown in row four of table 2. The coefficients on both variables have the anticipated signs and are statistically significant. The estimated coefficient on the lagged money term is smaller than that of the original specification, which suggests a quicker speed of adjustment. Also consistent with the Goldfeld equation results, the long-run income elasticity is estimated to be 0.62 . Once again, the addition of these variables produces both a decline in the sample-period standard error of the equation and a deterioration in the equation's post-sample predictive ability. In this specification, though, the deterioration is so marked that the RMSE is larger than that of the original Goldfeld equation.

The preceding results suggest that crucial to Hamburger's forecasting accuracy are (1) his treatment of the long-run income elasticity and (2) his exclusion of short-term interest rates, not the incorporation of longterm asset yields as he argues. ${ }^{21}$ This also explains why the substitution of a wealth variable in $\mathrm{Ham}$. burger's specification yields accurate post-sample predictions, while its inclusion in the Goldfeld equation does not.

\section{ACATH

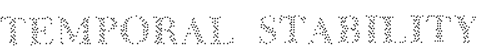

In the course of reviewing evidence on the temporal stability of the money demand relationship, this discussion like most recent literature has emphasized the relative post-1972 forecasting ability of alternative money demand specifications. This basis of comparison, however, assumes that the equation which performs best in terms of yielding the smallest postsample RMSE is the most stable relationship.

The inappropriateness of such an assumption should be obvious. If one is concemed with the temporal stability of a given relationship, one should be concemed

21All versions of the original Hanburger speciftation consiered in table 2 were also estinated assming a real mater than a nominal adustment mechanism. The resurts, available from the authors upon request, were similar in most respects to those reported above. with the predictive ability of that specification at different points in time, not its predictive ability relative to other specifications. Evidence that a given equation's predictions over a certain time interval are inferior to its predictions at earlier time periods (especially when such predictions are consistently to one side of the actual values) is highly suggestive of a breakdown in that relationship. A comparison of the predictive ability of any two equations over a given time period, however, will not allow one to deduce anything about the temporal stability of either equation.

In order to redirect attention to the basic issue of temporal stability, an alternative criterion to that of examining the relative forecasting ability of alternative specifications is now applied. This alternative test procedure will be used to examine the temporal stability of each specification discussed earlier.

The test used here is formulated and described in Brown, Durbin, and Evans."- To test the hypothesis of coefficient stability statistically, the BDE test re quires the calculation of the one-period-ahead forecast error of each specification. This prediction error is based on a regression over the time period 1 to $r$, where $\mathbf{r}=\mathrm{k}+\mathrm{l}, \ldots, \mathrm{T}$ ( $\mathrm{k}$ is the number of regressors, including the constant, and $\mathrm{T}$ is the sample size). In other words, if $k$ is equal to, say, five, then the first one-period-ahead prediction error would be based on a regression estimated over the sample 1 to 6 . The second prediction error is based on the regression estimated over the sample 1 to 7 and so on until the end of the sample ( $\mathrm{T}$ ) is reached.

The BDE statistic used, called the cusum-squares statistic, may be written as

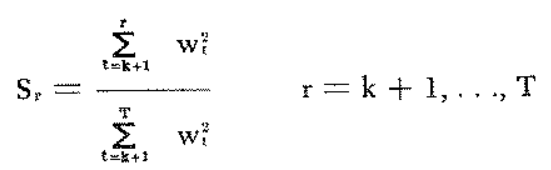

where $w_{\mathrm{t}}^{2}$ represents the squared one-period-ahead prediction errors. The custm-squares statistic is essentially the ratio of the squared one-period-ahead prediction errors based on the sample period $k+1$ to $r$, to the squared one-period-ahead prediction errors based on a regression estimated over the sample pe-

\footnotetext{
2-1) Brown, Durbin and Fvans, "Testing the Constancy of Regression Relationships." Recertly, Heller and Whan have applied this technicue to a short-rin money demand specification which indudes an approximation of the interest rate tem structure. See $\mathrm{H}$. Fobert Heller and Mohsin S. Wahn, "The Demand for Money and the Tem Structure of Interest Rates, Jounal of Political Economy (February 1979), pp. $109-29$.
} 


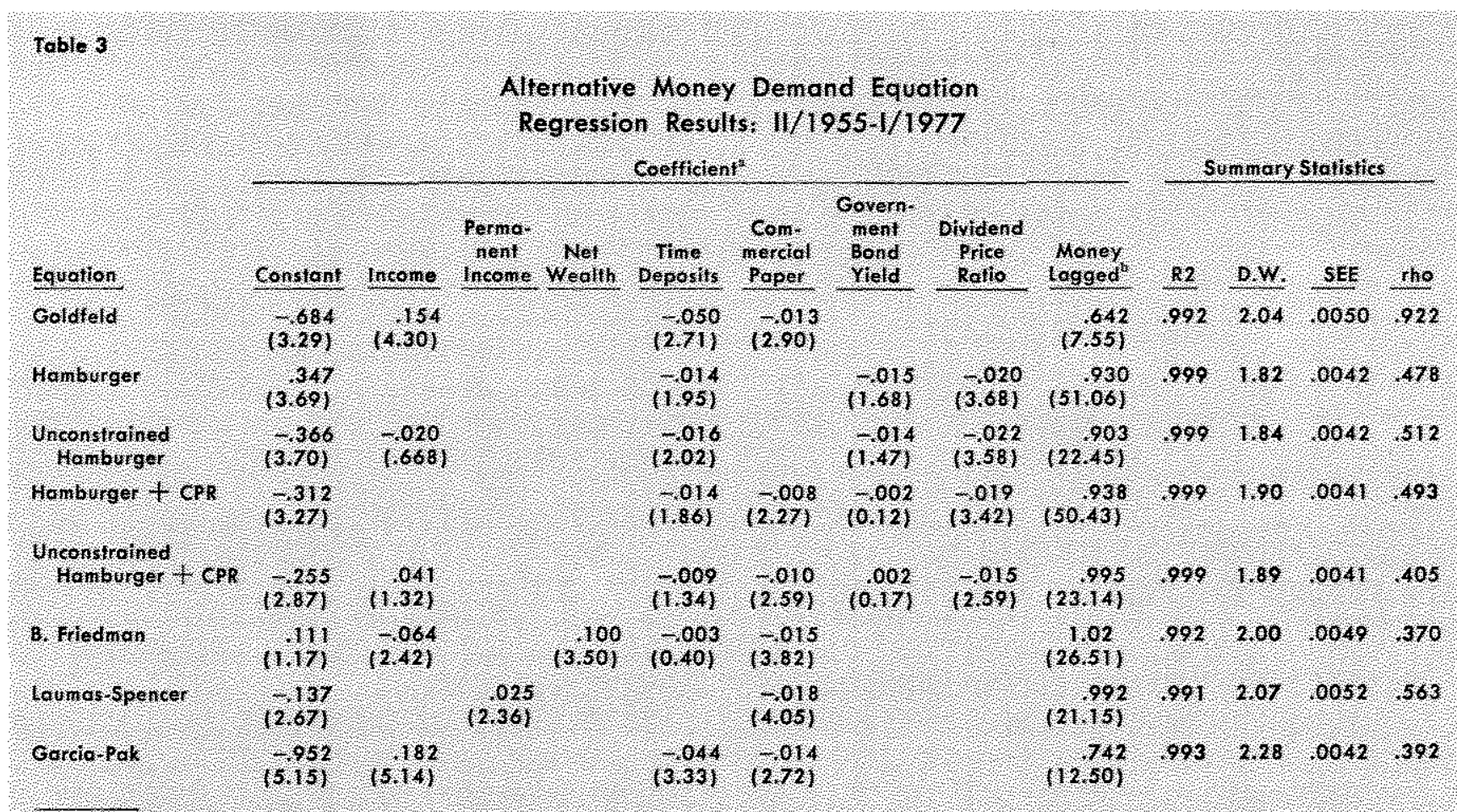

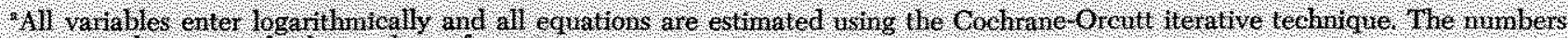
in parentheses are absolite valies of t-ratios.

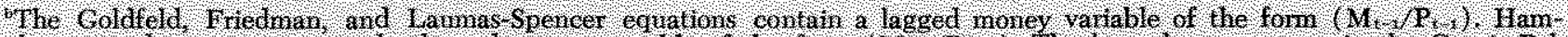

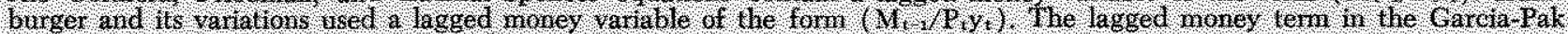
equation is of the form $(\mathrm{M}, 1 \mathrm{P}, \mathrm{H}$, where $\mathrm{M}=\mathrm{MI}+\mathrm{MA}$.

riod $\mathrm{k}+1$ to $\mathrm{T} .{ }^{23}$ The $\mathrm{S}_{\mathrm{r}}$ statistic is compared to a critical value and, if the estimated relationship is stable, the value of $S_{r}$ will be less than the predetermined critical value. ${ }^{24}$ This test may be illustrated graphically by plotting $S_{\mathrm{r}}$ against time, along with parallel sets of significance lines which provide the statistical "boundaries" used to indicate a break point at that given level of statistical significance.

Before applying the cusum-squares test, it was necessary to estimate each of the alternative specifications over the entire sample period (II/1955-I/1977). These regression results are presented in table 3 . In comparing the whole period regression results with those of the II/1955-IV/1972 period shown in table 1 , several changes are noticeable. In many cases, the full sample estimation results, in and of themselves, indicate a breakdown in the money demand relationship.

23 For a critical evaluation of the power of these tests, see $K$. Garbade, "Two Methods for Examining the Stability of Regression Coefficients," Journal of the American Statistical Association (March 1977), pp. 54-63 and John U. Farley, Melvin Hinich, and Timothy W. McGuire, "Some Comparisons of Tests for a Shift in the Slopes of a Multivariate Linear Time Series Model," Journal of Econometrics (Vol. 3, No. 3, 1975) pp. 297-318.

24John M. Evans, "User Guide to TIMVAR," Working Paper, Central Statistical Office (London, 1973).
In general, short-run income elasticity declines significantly as the sample period is extended. For example, when the income elasticity is freely estimated using the Hamburger specification (inclusive or exclusive of the commercial paper rate), the estimated coefficient on the income term becomes statistically insignificant and, in the latter equation, even takes on the "wrong" sign.

Another common feature of the full sample period results is the increase in the magnitude of the coeffcient on the lagged dependent variable. This phenomenon, which has been found in previous studies, indicates a slower speed of adjustment. ${ }^{25}$ In the Friedman specification, which incorporates the wealth variable, the lagged term coefficient becomes greater than unity, defying any meaningful interpretation within the stock-adjustment framework.

In general, many of the interest rate coefficients appear to be unstable. Although the coefficient on the commercial paper rate variable maintains its magnitude, the estimated coefficient on the commercial bank

"Garcia and Pak, "Some Clues in the Case of the Missing Money;" Heller and Kahn, "The Demand for Money and the Term Structure of Interest Rates;" and B. Friedman, "Crowding Out." 


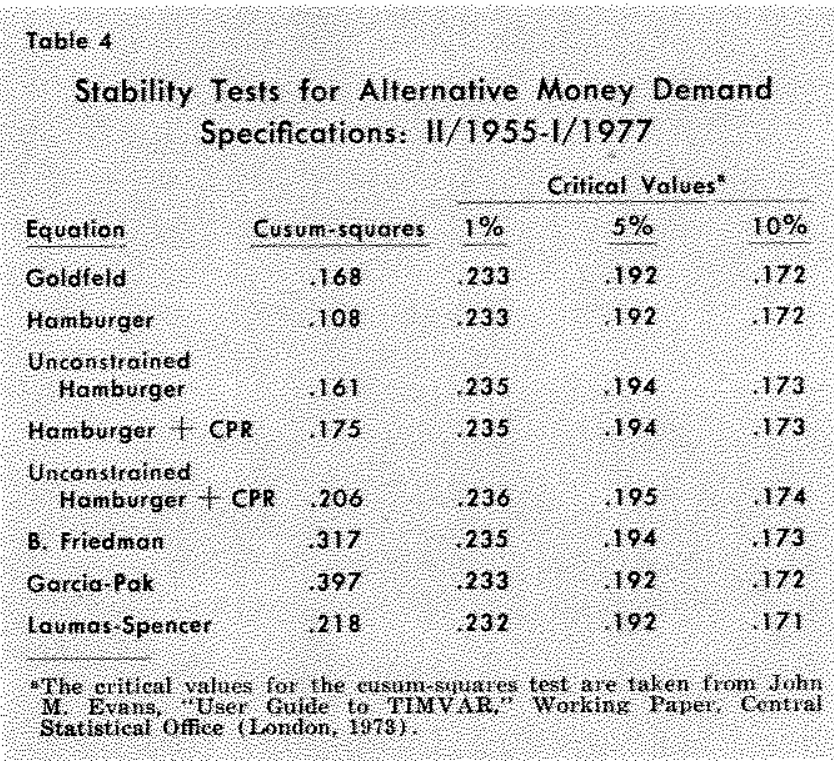

passbook rate shows a marked decline in a majority of the estimations, sometimes being insignificantly different from zero. In addition, the coefficient on the long-term government bond yield in all variations of the basic Hamburger specification fails to attain statistical significance over the longer sample period.

In contrast to the other money demand specifications, the Garcia-Pak and Goldfeld coefficient estimates are similar over both sample periods. The magnitudes of Garcia-Pak's lagged term, income, and time deposit rate coefficients all appear to change little when the I/1973-I/1977 observations are included. The largest change occurs for the coefficient on the commercial paper rate which declines by 30 percent when com paring the II/1955-IV/1972 results with those for II/1955-1/1977. Given certain reservations about this specification (see footnote 18 ), however, these results should be interpreted cautiously.

The coefficient estimates for Goldfeld's specification appear to be as stable as Garcia-Pak's. For instance, the estimated speed of adjustment for the full sample period regression is .358 compared with 335 for the II/1955-IV/1972 period. Given the relative stability of the other estimated coefficients, it is clear that the long-run elasticities for the interest rate variables do not vary dramatically between the two sample periods. For the commercial paper rate, the long-rum clasticities are 036 and .048 for the $I / / 1955-1 / 1977$ and $\mathrm{I} / 1955-\mathrm{IV} / 1972$ periods, respectively. The same measures for the time deposits variable are 140 and 119. The change in the estimate of the long-rmm in come elasticity is slighty larger. For the early sample period this parameter was .525 , compared with .430 over the full sample period. While this change may be significant, it is clearly smaller than that observed for the other specifications.

In order to carry out the cusum-squares test, it was assumed that the autocorrelation coefficient for each specification (given in table 3) was constant over the entire sample period. This assumption allows the transformation of the dependent and all independent variables to correct for serial correlation in the errors. This transformation was accomplished by subtracting the product of the estimated rho coefficient and the variable's previous value from the current value of the variable. ${ }^{26}$ Specifically, this procedure is given by the relationship

$$
x_{t}=x_{t}-\hat{\rho} x_{t-1}
$$

where $X_{t}$ represents the transformation of the variable $x_{t}$ and $\hat{\rho}$ is the estimated autocorrelation coefficient.

The statistical results for the cusum-squares tests are presented in table 4 . These tests indicate that several specifications are unstable over the full sample period: Hamburger with CPR (at a significance level of 10 percent), Unconstraned Hamburger with CPR ( 5 percent), Friedman (1 percent), Garcia-Pak ( 1 percent), and Laumus-Spencer ( 5 percent). Perhaps the most interesting finding is that the Goldfeld specification demonstrates no structural instability using this test. Indeed, the null hypothesis of stability cannot be rejected even at the 10 percent level of significance. ${ }^{2 T}$

While the statistical tests reported in table 4 indicate which equations demonstrate structural instability in the regression relationships over the entire sample period, they do not locate the probable point of departure from constancy. Such information is provided by charts 1-5. In each chart, the sample cusumsquares statistic $\left(S_{\mathrm{r}}\right)$ is plotted against time for each specification in which the hypothesis of stability was rejected by the cusum-squares test. In addition to the

-5uch a transfomation was required since the BDLt fests assime that the errors are serially independent. If the serial coetficient is constant throughou the period, this transformation yields serially independent error tems. This transformation, along with the presence of a lagged dependent variable, introduces nonstochastic independent variables, violating the assumption of the BDE test. However, we know of no other stability test that adequately deals with such problems.

It should be further noted that the Bols test is derived wa the assmotion that the variance of the errors are equal. In the case of money demand, the generwl iucrease in the standard erom of the exuation when the sample period is exterabed casts cursory dowbt on this assumption.

iAs regards the BDE tests for the coldeld equatim one shonld recall the above transformation required by the serially dependent eror tems. In perfoming this transfomation we took the tho value from table $3(0.922)$. This serial meficient was much larger than that fond for the earlier sample period (0.40). When the latter extmate is used, the

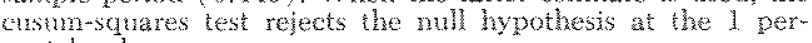
cent level. 
Chart 1

\section{Brown-Durbin-Evans Test of} Hamburger + CPR

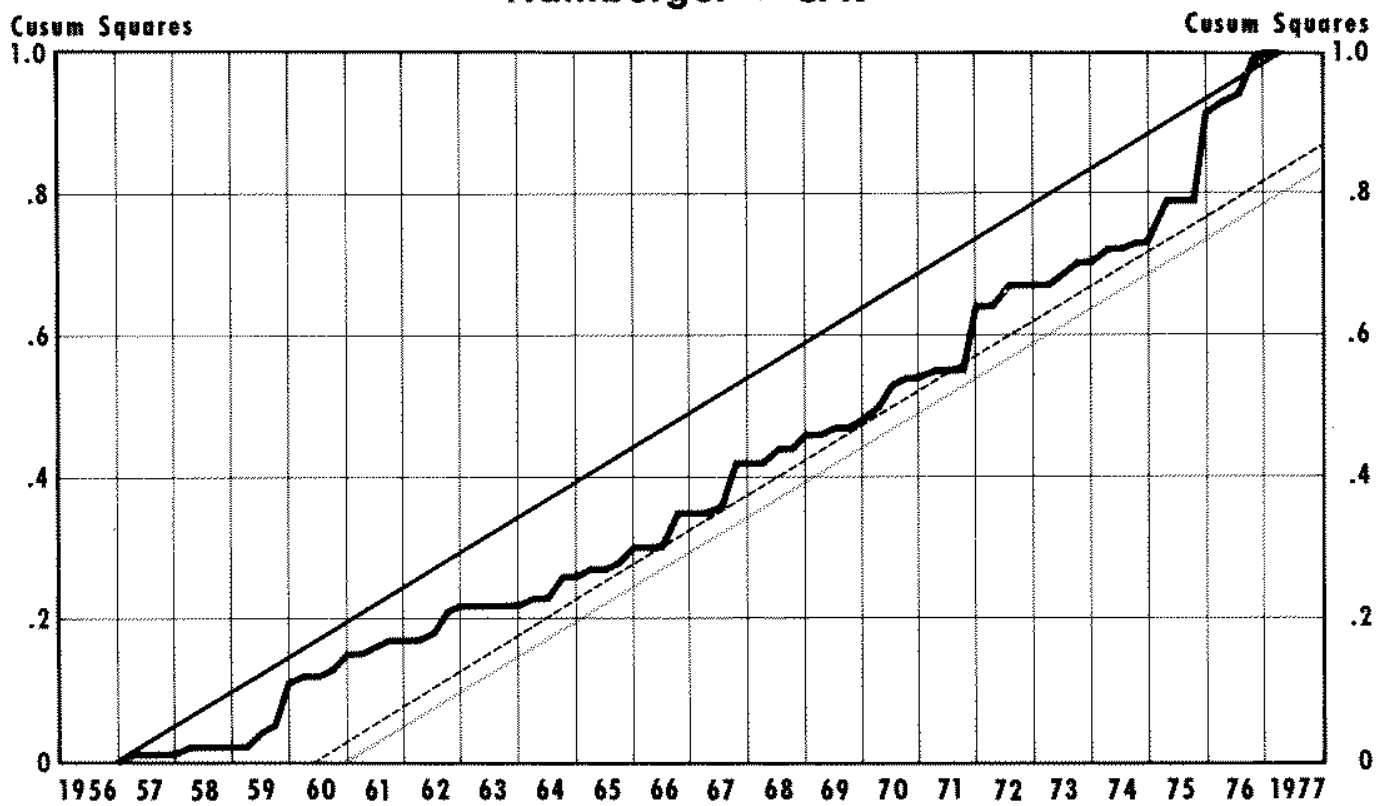

The doshed line represents the 10 percent level of significance, the green line represents the 5 percent lovel.

Latest data platted: Ist quarter Chart 2

Brown-Durbin-Evans Test of Unconstrained Hamburger + CPR

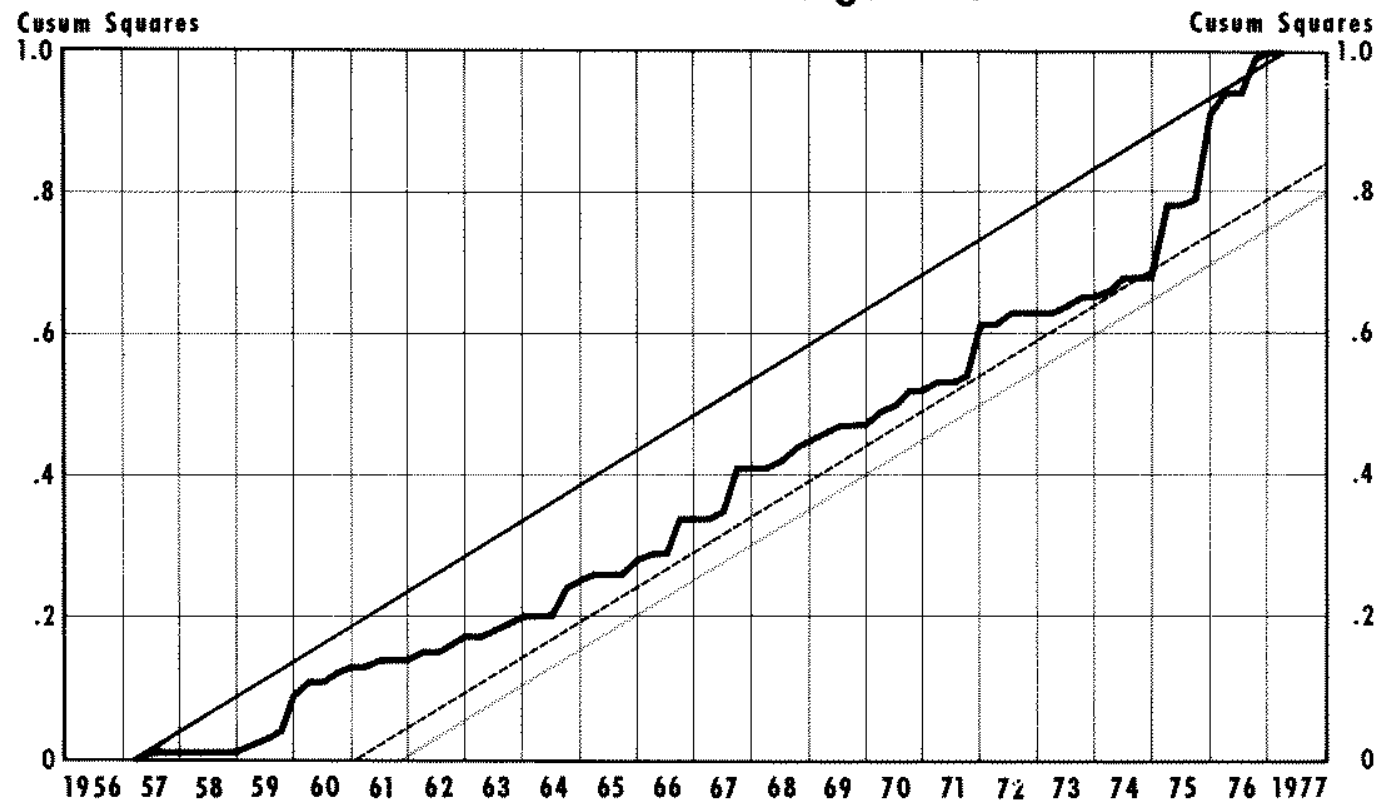

The doshed line represents the 5 percent level of significance, the green line represents the percant level.

Lolest dota plotted: lst quorter 


\section{Chort 3}

\section{Brown-Durbin-Evans Test of}

B. Friedman

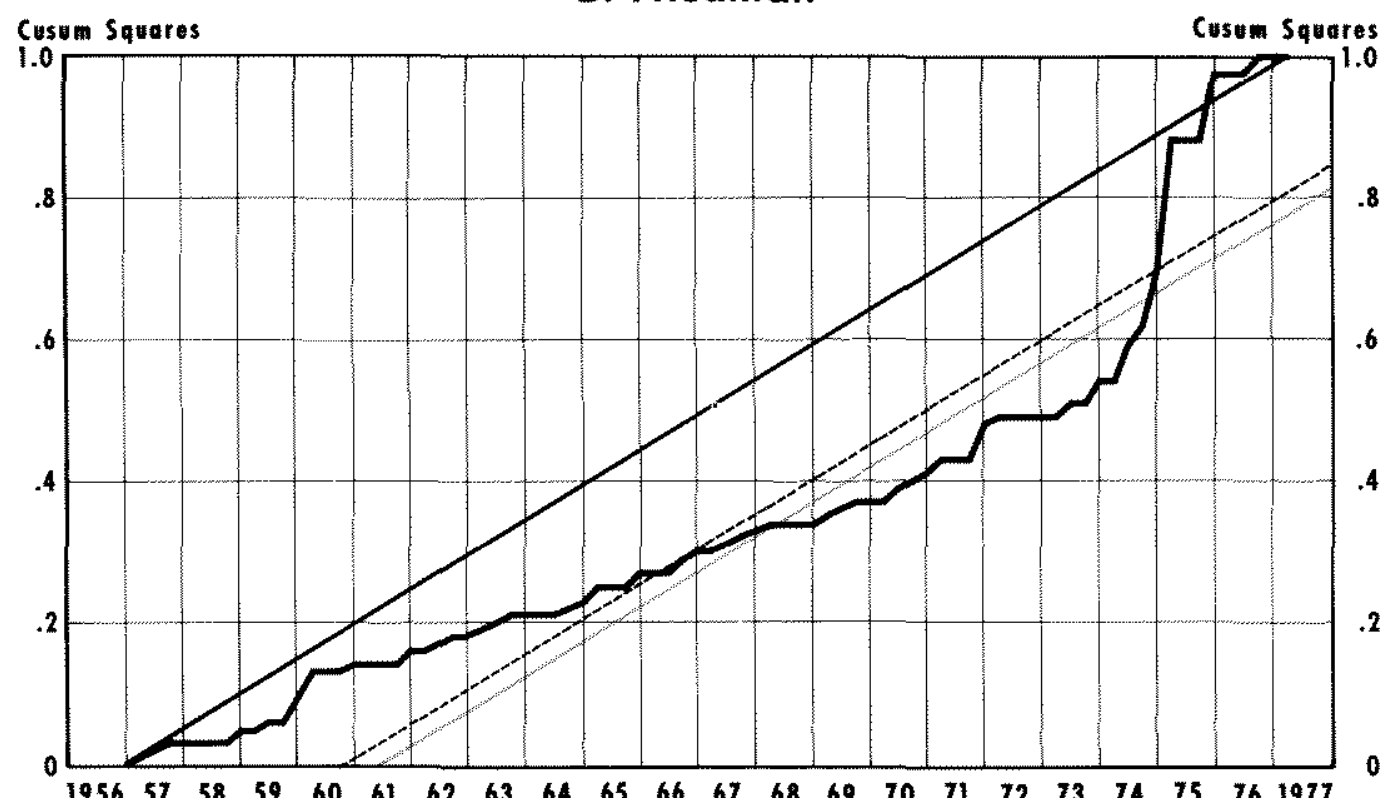

$\begin{array}{llllllllllllllllllllll}1956 & 57 & 58 & 59 & 60 & 61 & 62 & 63 & 64 & 65 & 66 & 67 & 68 & 69 & 70 & 71 & 72 & 73 & 74 & 75 & 76 & 1977\end{array}$

The dashed line represents the 5 percent level of significance, the green line represents the : percent level.

Lotes dote plotted: 15 quarter

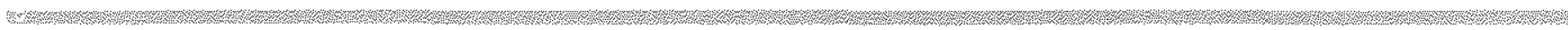

W Chart 4

\section{Brown-Durbin-Evans Test of GarciamPak}

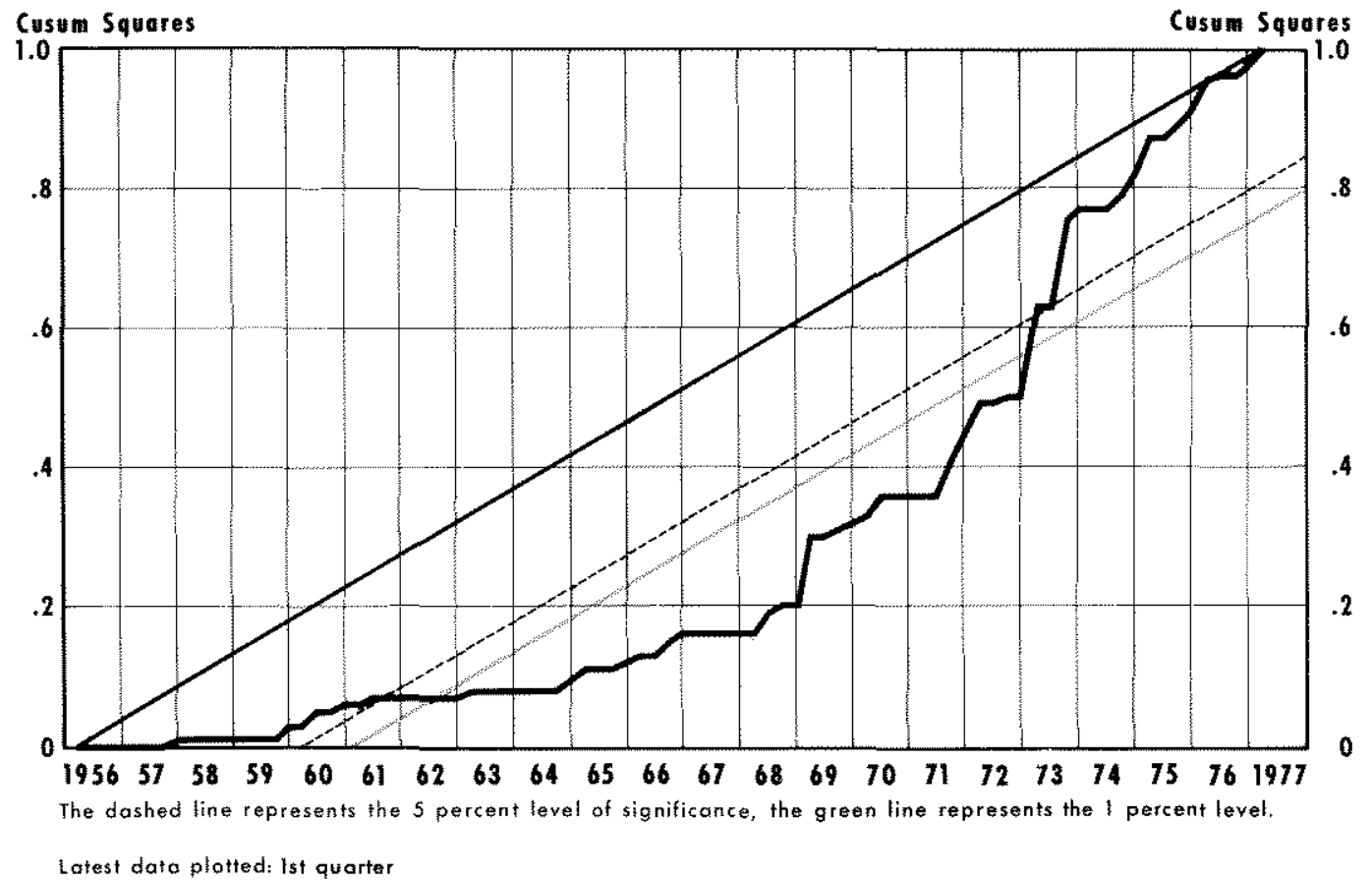




\section{Brown-Durbin-Evans Test of Laumas-Spencer}

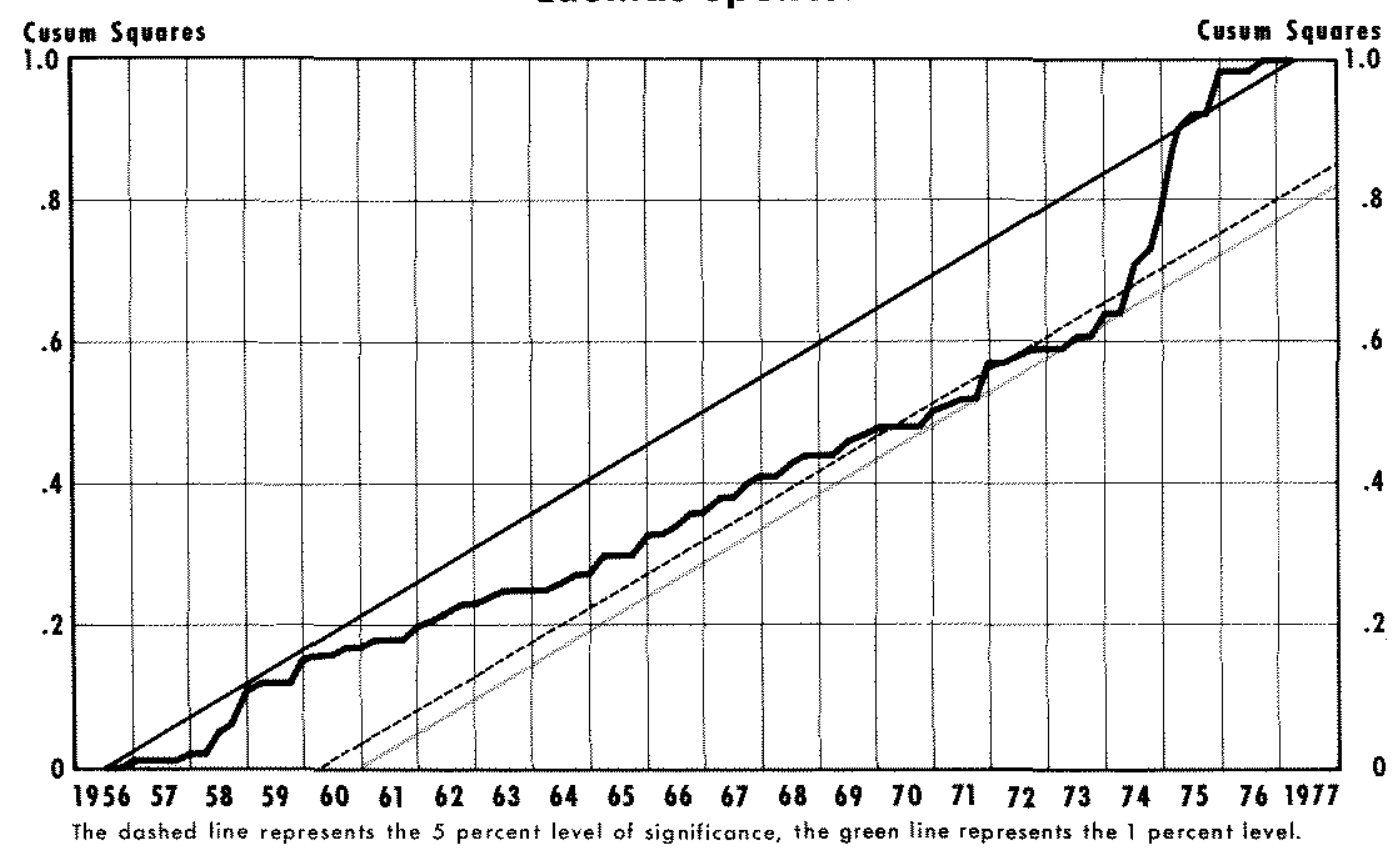

Lates data plotted; Ist quarter

plot of $S_{r}$, each chart plots the mean value of $S_{r}$ [i.e., $\left.\mathrm{E}\left(\mathrm{S}_{\mathrm{r}}\right)=(\mathrm{r}-\mathrm{k}) /(\mathrm{T}-\mathrm{k})\right]$ and two confidence lines which, for given levels of significance, are drawn parallel to the mean value line. When the plot of $S_{t}$ crosses one of these boundaries, the hypothesis of stability can be rejected at the appropriate significance level.

The charts reveal a varied picture of the timing of the possible structural shift. Chart 1 -representing the $S_{r}$ plot for the Hamburger with CPR specification - shows that at the 10 percent level the sample plot first intersects the statistical boundary in II/1966. At the 5 percent level the $S_{x}$ plot stays within the boundary, though nearly touching the 5 percent line in III $/ 1971$.

The $S_{\mathrm{F}}$ plot for the Unconstrained Hamburger with CPR (chart 2) crosses the 5 percent boundary in III/1974. Over the period 1966-74, however, the path of $S_{r}$ remains close to the 5 percent confidence band. Chart 3 , the $S_{r}$ plot drawn for the Friedman specification, indicates a structural shift (at the .5 percent level) in $1 / 1966$. Similar to chart 3 , the $S_{r}$ plot for the Garcia-Pak specification (chart 4) indicates that at the 1 percent level a shift in the underlying structural relationship occurred as early as IV/1962. Finally, the path of $S_{r}$ derived from the Laumus-Spencer equation (chart 5) crosses the 5 percent confidence line in $\mathrm{I} / 1970$, and intersects the 1 percent line in IV/1973.

An interesting feature of these results is that the equations which indicated structural instability shifted much earlier than might have been expected. The finding of break points during the mid-1960s is at odds with much of the recent literature which suggests structural shifts later in the sample period. ${ }^{28}$ The results presented here do, however, tend to agree with those of Slovin and Sushka who, using a money demand equation in which demand deposits were used as the definition of money, found evidence of structural instability during the early $1960 \mathrm{~s}^{29}$ Their work suggests that this shift was due to changes in Regulation $Q$ limits during this period.

${ }^{28}$ Applying the Quandt $\log$-likelihood ratio test to these equa tions suggests the following possible points to structural shift in the regression relationships: Hamburger with CPR, I/1975; Unconstrained Hamburger with CPR, III 1974 ; B. Friedman, 1/1974; Carcia-Pak, IV/1967; and Laumuss-Spencer, IV/ 1973. While these results are in general agreement with those found by others (e.g. Enzler, Johnson, and Paulus, Goldfeld, Hamburger), the findings suggest that the structural instability of these models may have occurred at tariots times over the sample period.

"Myron B. Slovin and Marie Elizabeth Sushka, "The Structural Shift in the Demand for Money," The Journal of Finence (June 1975), pp. $721-31$. 
In summary, these results indicate that many of the money demand specifications which have been offered as possible explanations of the missing money puzzle have actually been subject to significant structural changes over the II/1955-I/1977 sample period. A most interesting finding is that the regression coeffcients on the Goldfeld specification do not change markedly when the sample period is extended to include the post-1973 period. In addition, when the autocorrelation coefficient was constrained to be 0.92 , the equation did not indicate instability according to the cusum-squares test.

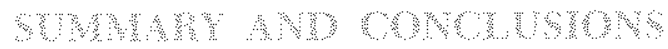

This article has examined the temporal stability of several alternative money demand relationships. Recent literature on money demand has drifted away from this concern and has focused too narrowly on the issue of predicting post-1972 real money balances. The formal test results presented in this article suggest that such a shift in emphasis has been misleading.

The findings in this paper indicate that, while several of the respecifications of the traditional transaction money demand relationship have yielded accu- rate post-1972 forecasts relative to those found for the real adjustment version of the Goldfeld specification, none of the modifications which stood up under critical review was temporally stable over the entire II/1955-I/1977 sample period. The modifications considered here included changing the measurement of the scale variable, broadening the asset range to include long-term yields, and redefining money to incorporate repurchase agreements.

The test employed in this paper (the BDE cusumsquares test) did not allow us to reject the hypothesis that the underlying relationship between the predetermined variables and real money balances, given by the conventional Goldfeld specification, was stable. In fact, the regression coefficients for the sample period including the turbulent period 1/1973-I/1977 were markedly similar to those found when the sample period was ended in IV/1972. This finding indicates that the purported breakdown in this specification was overemphasized as a result of the reliance on the shortterm predictive ability of the equation. In terms of policy implications, this finding suggests that longterm monetary policy prescriptions based on the assumption of a stable money demand relationship will be more reliable than previous analysis has implied.

\section{Appendix: Data Definitions and Sources}

Commercial paper rate (CPR) - 4-6 month prime commercial paper rate. Prior to $111 / 1974$ average of most representative daily offering. After III/1974 average of midpoint of range of daily deater closing rates.

Source: Federal Reserve Bank of New York

Long-term U.S. government bond yields (RGL)

Source: Federal Reserve Bulletin

Money stock (M1) - narrowly defined money balances (in billions of dollars), seasonally adjusted, quarterly average of monthly figures.

Source: Federal Reserve Board

Income $(y)$ - gross national product in billions of 1972 dollars at seasonally adjusted annual rates.

Source: U.S. Department of Commerce, Bureau of Economic Analysis
Price level (P) - implicit gross national product price deflator $(1972=100)$

Source: U.S. Department of Commerce, Bureat of Economic Analysis

Time deposit rate (RTD)

Source: Stephen M. Goldfeld

Dividend price ratio on common stocks (DPR)

Source: Federal Reserve Bulletin

Permanent income - exponentially weighted average of past values of real gross national product.

Source: David E. Spencer

Howsehold net worth (wealth)

Source: Federal Reserve Board

Immediately available funds (IAF)

Source: Garcia-Pak, "The Ratio of Currency." 